\title{
A BUSCA DE AUTO-SUFICIÊNCIA EM FARINHAS PANIFICÁVEIS
}

\author{
Benedicto Heloiz Nascimento*
}

\begin{abstract}
RESUMO
A busca de sucedaneos para mercadorias de dificil produçäo no Brasil tenderia a ocorrer periódica e coincidentemente com problemas e dificuldades de importaçäo. Aqui, figurariam as sucessivas tentativas de reduzir o consiumo de trigo estrangeiro. através da utilizaçāo de outras farinhas panificáveis, onde a de mandioca ganharia notável destaque, justificado principalmente pela abundancia e baixo preço do tuberrculo. Trata-se de um recurso que vem sendo pesquisado e usado no Brasil desde a última metade do século passado, ao qual continuou-se a recorrer, eventualmente, mesmo após a Segunda Guerra Mundial.
\end{abstract}

Unitermos: substituiçāo de importaçōes - tecnologia - indístria - alimentaçäo

O conhecimento no Brasil da possibilidade do uso de sucedâneos misturados à farinha de trigo para a fabricação de pão seria bastante antigo, entretanto o seu uso de modo sistemático, mesmo que por períodos curtos de tempo, demoraria a ocorrer.

Na sessão de 01/12/1871 do Conselho Administrativo da Sociedade Auxiliadora da Indústria Nacional, seria "lido parecer da secção de indústria fabril sobre o privilégio pedido por Casimiro Cambert, dono de padaria, para só ele fabricar pão composto em sua maior parte de mandioca por um processo por ele descoberto". Acontecimento que teria secundado o feito de João da Costa Freitas, que na Exposição Nacional de 02/12/1861 apresentava farinha de mandioca panificável e pão preparado com $50 \%$ deste produto, apesar de, segundo ata da sessão acima referida da Sociedade Auxiliadora da Indústria Nacional, menos perfeito que o de Cambert. 1

(*) Professor Assistente Doutor do IEB (área de História).

(1) Ata da sessāo de 20 de novembro de 1871 do Conselho Administrativo da Sociedade Auxiliadora da Indústria Nacional. In: O AUXILIADOR DA INDÚSTRIA NACIONAL. Rio de Janeiro, Sociedade Auxiliadora da Indústria Nacional, 39(12):531-2, dez. 1871 (Agradeço à prof" Lucy Maffei Hutter a localizaçāo e o empréstimo do texto da ata referida). 
Durante a Guerra Mundial de $1914 / 18$ usou-se farinha de trigo misturada à de mandioca, com o fim de produzir quantidade suficiente de pão, necessária ao consumo do povo, dentro de um quadro geral em que também havia escassez de farinha de mandioca. 2

Ainda nesse período, empregou-se, principalmente no Estado do Pará, farinha mista de arroz e trigo na fabricação de pão, que continha apenas $40 \%$ do segundo ingrediente. ${ }^{3}$

Esse caminho para a solução da escassez de farinha de trigo na produção de pães, através da adição de sucedâneos abundantes no país, foi objeto de estudos e experimentos relativamente bem sucedidos. Aí observou-se em 1916 o caso de Alexandre Colaferri, de Campinas, o qual, para contornar o problema da falta de matéria-prima básica para o preparo de macarrão, usaria massa mista, contendo $55 \%$ de farinha de trigo de primeira qualidade, $5 \%$ de farinha de arroz e $40 \%$ de farinha de milho finamente peneirada. 4

Para essa finalidade ter-se-ia que usar os produtos nacionais mais adequados e abundantes, que seriam o arroz, o milho e principalmente a mandioca, tubérculo que a princípio apresentava utilização trabalhosa, por ser de difícil conservação e oferecer pequena resistência ao transporte, problemas que só acabariam removidos pela criação da indústria de farinha de raspas de mandioca, isto $\varepsilon$, de lascas de mandioca descascada, secas ao Sol ou em forno. 5

Esses sucessos e aquela falta de um insumo básico, embora de fácil obtenção, fizeram com que nos primeiros anos da década de 1920, o Governo Federal se comprometesse a auxiliar as "empresas fabricantes de farinha de mandioca, polvilho, farelo de ramas de mandioca e outros de seus produtos, que se obrigassem a empregar maquinismos ou fazer adaptaçōes capazes de [permitir] produzir $30 \%$ no mínimo de farinha de mandioca panificável". Essas firmas teriam $75 \%$ do custo de suas instalaçōes financiados a juros de $6 \%$ ao ano, devendo o empréstimo ser resgatado seis anos após a inauguração da fábrica. ${ }^{6} \mathrm{Em}$ 1924, Arthur Bernardes, na Mensagem Presidencial, pedia ao Congresso autorização para iniciar as operaçōes de crédito acima referidas. Ele afirmava, ainda, terem continuado os ensaios de confecção e promoção do pão misto, que esperava fosse, já naquele ano, vendido na cidade do Rio de Janeiro. 7

A partir de 1930 a Secretaria da Agricultura do Estado de São Paulo tamberm teria passado a patrocinar trabalhos sobre o uso da farinha mista em panificaçāo. A Comissāo do Pão de Guerra, criada em 1932, adotaria para

(2) MÉLlO, A. da Silva: A alimentaçāo no Brasil. Rio de Janeiro, José Olympio, 1961. p. 160.

(3) AMARAL, F. Pompeo do. O problema da alimentaçäo. Rio de Janeiro, José Olympio, 1963. p. 404 .

(4) Idem. Ibidem. p. 383, 405-7.

(5) Idem. Ibidem, p.405, 513 .

(6) Regulamento da Lei n 4.540, de 06/02/22, aprovado pelo Decreto n-16.131, de 25/08/23.

(7) BERNARDES, A. Mensagem ao Congresso Nacional de 03/05/24. Citado por: ANDRADE, A. Contribuiçāo d história administrativa do Brasil. Rio de Janeiro, José Olympio, 1950. v. 1, p. 112. 
isso uma farinha de trigo com taxa de extração igual a $80 \%$, mais $5 \%$ de fubá, porcentagem que aumentaria com o crescimento da escassez de trigo. 8 Em 1933 o novo Interventor em São Paulo instituiria, através do Decreto Estadual no 5.879 de 12/04/33, a Comissão do Pão Misto a fim de promover "Exposição-Concurso" para demonstrar as possibilidades do pão misto como sucedâneo daquele de farinha de trigo. Essa Comissão deveria, ainda, "auxiliar a organização de concorrências públicas que [seriam] abertas para o fornecimento do pão misto aos quartéis, cadeias, penitenciárias e estabelecimentos oficiais, assim como a organização dos serviços de fiscalização e de assistência técnica [à] fabricação do pão misto destinado ao consumo em geral".

Após 1933 começaram-se, no Ministério da Agricultura, estudos sobre o rendimento das culturas das diferentes variedades de mandioca, aumento de sua produção e sua industrialização sob a forma de farinha, fécula (amido, polvilho, tapioca) e álcool. ${ }^{9}$

Nesse mesmo ano, Alexandre Colaferri preconizava para o pão a farinha que já usava nas suas massas e biscoitos. Chegar-se-ia, também, à conclusão de que pães e massas produzidos com $50 \%$ de farinha de milho e $50 \%$ de farinha de trigo de $3^{a}$ qualidade, isto $\varepsilon$, de extração mais alta, poderiam ser vendidos $30 \%$ mais baratos que aqueles de trigo puro. ${ }^{10}$

Produção Agrícola Brasileira (em t)

\begin{tabular}{lllllll}
\hline Ano & Mandioca & Milho & $\begin{array}{c}\text { Arroz com } \\
\text { casca }\end{array}$ & Trigo & Total \\
\hline 1925 & $2.898 .570 *$ & 4.480 .915 & 709.120 & 147.460 & 8.236 .065 \\
1931 & 5.209 .500 & 4.749 .995 & 1.078 .458 & 141.580 & 11.179 .533 \\
1935 & 4.541 .000 & 5.932 .908 & 1.366 .770 & 146.130 & 11.986 .808 \\
1936 & 4.946 .850 & 5.721 .202 & 1.213 .580 & 143.554 & 12.025 .186 \\
1937 & 5.013 .042 & 5.775 .910 & 1.231 .799 & 149.364 & 12.170 .115 \\
1938 & 6.020 .611 & 5.559 .835 & 1.529 .274 & 137.268 & 13.246 .988 \\
1939 & 7.122 .316 & 5.393 .553 & 1.484 .514 & 101.107 & 14.101 .490 \\
1940 & 7.331 .862 & 4.875 .533 & 1.319 .973 & 101.739 & 13.629 .107 \\
1941 & 7.762 .561 & 5.438 .010 & 1.687 .534 & 231.454 & 15.119 .859 \\
1942 & 7.915 .672 & 5.276 .399 & 1.881 .255 & 216.867 & 15.290 .193 \\
1943 & 8.936 .239 & 5.210 .396 & 1.893 .834 & 223.108 & 16.263 .577 \\
1944 & 10.333 .356 & 5.574 .741 & 2.110 .467 & 170.586 & 18.189 .150 \\
1945 & 11.414 .680 & 4.846 .557 & 2.146 .965 & 233.298 & 18.641 .500 \\
\hline
\end{tabular}

Fonte: ANUÁRIO ESTATÍSTICO DO BRASIL 1939/1940. Rio de Janeiro, IBGE, v. 5, [1941]. p. 1.312-4. Idem 1956. v. 17, 1956. p. 496, 503-5. (*) 1920.

(8) AMARAL, F. Pompeo do. Op. cit. p. 400, 405.

(9) ANDRADE, A. Op. cit. v. 1, p. 112-3.

(10) AMARAL, F. Pompeo. Op. cit. p. 407. 
Evolução da Quantidade de Produção Brasileira dos Principais Cereais e Tubérculos Panificáveis $(1935=100)$

\begin{tabular}{lrrrrr}
\hline Ano & Mandioca & Milho & $\begin{array}{c}\text { Arroz com } \\
\text { casca }\end{array}$ & Trigo & Total \\
\hline 1925 & $55,64 *$ & 75,53 & 51,88 & 100,91 & 68,71 \\
1931 & 114,72 & 80,06 & 78,91 & 96,89 & 93,26 \\
1935 & 100,00 & 100,00 & 100,00 & 100,00 & 100,00 \\
1936 & 108,94 & 96,43 & 88,79 & 98,24 & 100,32 \\
1937 & 110,39 & 97,35 & 90,12 & 102,21 & 101,53 \\
1938 & 132,58 & 93,71 & 111,89 & 93,93 & 110,51 \\
1939 & 156,84 & 90,91 & 108,61 & 69,19 & 117,64 \\
1940 & 161,46 & 82,18 & 96,58 & 69,62 & 113,70 \\
1941 & 170,94 & 91,66 & 123,47 & 158,39 & 126,14 \\
1942 & 174,32 & 88,93 & 137,64 & 148,41 & 127,56 \\
1943 & 196,79 & 87,82 & 138,56 & 152,68 & 135,68 \\
1944 & 227,56 & 93,96 & 154,41 & 116,74 & 151,74 \\
1945 & 251,37 & 81,69 & 157,08 & 159,65 & 155,52 \\
\hline
\end{tabular}

Fonte: ANUÁRIO ESTATÍSTICO DO BRASIL 1939/1940. Rio de Janeiro, IBGE, v. 5, [1941]. p. 1.312-4. Idem 1956. v. 17, 1956. p. 496, 503-5.

(*) 1920.

Participação na Quantidade Total da Produção

Brasileira dos Principais Cereais e Tubérculos Panificáveis

\begin{tabular}{|c|c|c|c|c|c|}
\hline Ano & Mandioca & Milho & $\begin{array}{l}\text { Arroz com } \\
\text { casca }\end{array}$ & Trigo & Total \\
\hline 1925 & $35,19 *$ & 54,41 & 8,61 & 1,79 & 100,00 \\
\hline 1931 & 46,60 & 42,49 & 9,65 & 1,26 & 100,00 \\
\hline 1935 & 37,88 & 49,50 & 11,40 & 1,22 & 100,00 \\
\hline 1936 & 41,14 & 47,58 & 10,09 & 1,19 & 100,00 \\
\hline 1937 & 41,19 & 47,46 & 10,12 & 1,23 & 100,00 \\
\hline 1938 & 45,45 & 41,97 & 11,54 & 1,04 & 100,00 \\
\hline 1939 & 50,51 & 38,25 & 10,52 & 0,72 & 100,00 \\
\hline 1940 & 53,80 & 35,77 & 9,68 & 0,75 & 100,00 \\
\hline 1941 & 51,34 & 35,97 & 11,16 & 1,53 & 100,00 \\
\hline 1942 & 51,77 & 34,51 & 12,30 & 1,42 & 100,00 \\
\hline 1943 & 54,95 & 32,04 & 11,64 & 1,37 & 100,00 \\
\hline 1944 & 56,81 & 30,65 & 11,60 & 0,94 & 100,00 \\
\hline 1945 & 61,23 & 26,00 & 11,52 & 1,25 & 100,00 \\
\hline
\end{tabular}

Fonte: ANUÁRIO ESTATÍSTICO DO BRASIL 1939/1940. Rio de Janeiro, IBGE, v. 5, [1941]. p. 1.312-4. Idem 1956. v. 17, 1956. p. 496, 503-5.

(*) 1920. 
Em 1937, com a Lei no 470 de 09/08/37, o Executivo procurava fomentar a cuitura do trigo no Brasil, determinando a criação de um laboratório central especializado para fazer "estudos de panificação das diferentes variedades de trigo colhidas no país e controlar as conclusōes das pesquisas químico-biológicas procedidas nas estaçōes experimentais". Além daquelas duas já existentes, em São Paulo e no Rio Grande do Sul, essa mesma lei criava outras cinco estaçōes experimentais de trigo distribuídas entre os Estados de Santa Catarina, Paraná, Goiás, São Paulo e Rio Grande do Sul. Estas seriam secundadas por 40 postos de multiplicação de sementes espalhados por nove Unidades Federativas, dez no Rio Grande do Sul, sete em Santa Catarina, nove no Paraná, seis em São Paulo, quatro em Minas Gerais, restando apenas um por Estado em Goiás, Espírito Santo, Pernambuco e Bahia. Além disso dever-se-ia criar um laboratório central para proceder a estudos de panificação das diferentes variedades de trigo colhidas no país e controlar as pesquisas desenvolvidas nas estaçöes experimentais.

Cada moinho deveria, a partir de $01 / 06 / 37$, consumir pelo menos $5 \%$ de trigo nacional sobre o total do produto estrangeiro beneficiado, caso o preço do primeiro não excedesse o do segundo. Ao mesmo tempo seria premiada a produtividade dos cultivadores do referido cereal, que teria suas sementes transportadas graciosamente nas ferrovias e linhas de navegação, enquanto que maquinaria agrícola e moinhos de beneficiamento seriam vendidos a agricultores pelo preço de custo e a prazo, gozando a produção nacional de um desconto de $60 \%$ nos fretes.

$\mathrm{Na}$ ausência de interesse privado, o Ministério da Agricultura instalaria moinhos onde a expansão da cultura do trigo dependesse desse meio de beneficiamento, enquanto que a farinha estrangeira pagaria imposto de $\$ 600$ (seiscentos réis) sobre cada saco de $44 \mathrm{~kg}$.

A farinha de trigo produzida no Brasil, conforme o Decreto n-26 de $30 / 11 / 37$, só deveria ser utilizada nos trabalhos de panificação com a adição, de até $30 \%$, de fécula ou farinha de produto nacional apropriado.

Logo, através do Decreto no 2.307 de 03/02/38, seria organizado no Ministério do Trabalho, Indústria e Comércio o Serviço de Fiscalização do Comércio de Farinhas (SFCF). Entidade constituída de um chefe, fiscais (engenheiros civis, industriais, agrônomos ou químicos industriais) e auxiliares.

Fora isso, o Ministério do Trabalho, Indústria e Comércio estabeleceria um Conselho Consultivo, incumbido do estudo das medidas a serem adotadas peio Governo para a indústria e comércio de farinhas. Colegiado presidido pelo chefe do Serviço de Fiscalização do Comércio de Farinhas, do qual também participaria um representante de cada uma das seguintes instituiçōes: Ministério da Agricultura, Departamento Nacional de Saúde, Instituto Nacional de Tecnologia, Sindicatos ou Cooperativas Agrícolas, Moinhos, Sindicatos de Panificadores e Confeiteiros.

O SFCF deveria fixar a qualidade, quantidades disponíveis e preços de entrega aos moageiros das farinhas, féculas e amidos de produçāo nacional que deveriam ser adicionados pelos moinhos à farinha de trigo. Ele deveria, para isso, determinar as taxas de extraçāo das farinhas de trigo produzidas no país, organizar estatísticas de importaçāo de trigo (em grão ou em farinha) e da produção de seus sucedâneos (mandioca, milho, arroz...) e respectivos derivados, além de manter um registro das fábricas nacionais fornece- 
doras destas mercadorias e estipular, com o auxílio de um serviço de previsão agrícola e industrial, as quotas de produtos nacionais a serem misturados com a farinha de trigo.

O Governo vedava o uso de conservantes, ou outros produtos estranhos, nas féculas, farinhas e amidos, os quais, para compor a mistura panificável, deveriam ser elaborados com matérias-primas e conforme tecnologia consideradas adequadas. Além disso, obrigava-se o uso de farinha mista com até $10 \%$ de féculas ou farinhas de produçāo nacional na confecçāo de massas comuns, doces e biscoitos. Ao mesmo tempo os importadores de farinha de trigo estrangeira deveriam providenciar a sua mistura com os produtos nacionais, féculas e farinhas, que gozavam de preferência e abatimento de $20 \%$ sobre as tarifas no transporte ferroviário e de cabotagem do país.

Pelo já referido Decreto n $2.307 / 38$, ficavam isentos da adição de sucedâneos, as unidades das regiôes tritícolas que moessem exclusivamente o trigo nelas cultivado ou que, localizadas nos Estados produtores, moessem pelo menos $30 \%$ de trigo nacional. Fora isso, o Governo concederia isenção de impostos de importação para a maquinaria, produtos químicos e materiais de laboratório e de controle destinados aos estabelecimentos dedicados a fabrico de féculas e farinhas panificáveis.

A aquisição e o consumo do trigo em grão nacional tornar-se-ia obrigatória para as empresas moageiras através do Decreto-Lei no 955 de 15/12/38, que, também, forçaria a adição de sucedâneo escolhido pelo SFCF, na mesma base já estabelecida para o produto estrangeiro.

Em novembro de 1939 o SFCF, pela Circular $n=21$, permitia atingir-se na moagem de trigo taxa de extração, isto $\varepsilon$, de obtenção de farinha do grão de trigo, de $84 \%$, a fim de conseguir maior quantidade do produto e melhor enfrentar sua escassez, provocada pelo conflito mundial e dificuldades de importação. O mesmo expediente seria seguido por Fernando Costa, no Governo de São Paulo, que procuraria promover em panificação o uso de farinha a $80 \%$, para ser mais tarde aumentada para $85 \%$ de taxa de extração. Assim podia-se fabricar um pão mais barato e mais nutritivo, embora de menor aceitação pelo público, o qual relacionava qualidade e pureza do produto com o que denominava farinha ideal, de mais baixa extração (60\% a $70 \%)$, alva, descorticada, sem farelo ou remoído. Farinha esta que dava um pão de sabor, contextura e aspecto com o qual as pessoas estavam acostumadas, ficando o farelo destinado à alimentaçāo de animais. ${ }^{11}$

Procurava-se, também, facilitar a aquisição e eliminar problemas e custos de transporte, ao mesmo tempo que se reconhecia a integração dos moinhos das zonas produtoras com a economia regional tritícola. Dentro deste propósito, o Decreto-Lei no 3.984 de 30/12/41 determinava que a produção nacional de trigo seria adquirida e beneficiada pelos pequenos moinhos situados nas zonas de produção e que não trabalhassem com matéria-prima importada.

$O$ instrumento legal acima referido obrigava as empresas moageiras importadoras de trigo a recolher ao Banco do Brasil $15 \$ 000$ (quinze mil réis) por saco de $60 \mathrm{~kg}$ de grão nacional utilizado conforme descrição anterior.

(11) Idem. Ibidem. p. 400. MELLO, A. da Silva. Op. cit, p. 160-1. 
Estas quantias corresponderiam às quotas "atribuídas" pelo SFCF a essas empresas, devendo ser utilizadas em proveito da cultura, do beneficiamento do trigo nacional e como compensação aos pequenos estabelecimentos pela moagem das quotas adjudicadas às empresas que trabalhavam com cereal estrangeiro.

Importaçāo Brasileira de Trigo (em t)

\begin{tabular}{ccccc}
\hline Ano & $\begin{array}{c}\text { Farinha de } \\
\text { trigo }\end{array}$ & $\begin{array}{c}\text { Equivalente da } \\
\text { farinha em grāo }\end{array}$ & $\begin{array}{c}\text { Trigo em } \\
\text { grāo }\end{array}$ & $\begin{array}{r}\text { Total Estimado } \\
\text { de trigo em grão }\end{array}$ \\
\hline 1925 & 164.036 & 218.715 & 521.154 & 739.869 \\
1931 & 61.307 & 81.743 & 795.893 & 877.636 \\
1935 & 45.464 & 60.619 & 881.723 & 942.342 \\
1936 & 50.813 & 67.751 & 919.860 & 987.611 \\
1937 & 41.307 & 55.076 & 930.818 & 985.894 \\
1938 & 42.982 & 57.309 & 1.037 .160 & 1.094 .469 \\
1939 & 33.738 & 44.984 & 966.835 & 1.011 .819 \\
1940 & 18.029 & 24.039 & 857.937 & 881.976 \\
1941 & 17.962 & 23.949 & 894.895 & 918.844 \\
1942 & 15.610 & 20.813 & 945.733 & 966.546 \\
1943 & 25.588 & 34.117 & 1.042 .601 & 1.076 .718 \\
1944 & 72.841 & 97.121 & 1.200 .937 & 1.298 .058 \\
1945 & 141.693 & 188.924 & 1.090 .327 & 1.279 .251 \\
\hline
\end{tabular}

Fonte: ANUÁRIO ESTATÍSTICO DO BRASIL 1956. Rio de Janeiro, IBGE, v. 17,1956 . p. $530-1$. Para a taxa de conversão da farinha para trigo em grão usou-se a proporção encontrada em BRASIL. Ministério das Relaçōes Exteriores. Brasil 1939/1940. Rio de Janeiro, Estabelecimento de Artes Gráficas C. Mendes Jr., 1940. p. 98, onde cada unidade de grão daria aproximadamente 0,75 de farinha, equivalendo, assim, esta última a 1,33 ou $1 / 3$ unidade de grāo.

Tudo isso seria feito dentro do objetivo de tornar o país menos dependente do exterior naquilo que se referia a farinhas panificáveis, problema que se revelava de difícil solução. Esta exigiria um esforço criativo nem sempre bem apoiado pela realidade constatada no aparelho produtor, hábitos e valores dos consumidores. Faltaria ainda maior constância e manutenção das diretrizes da política econômica governamental, a qual tenderia a ressentir-se de uma verdadeira capacidade de resistir às pressōes de interesses contrários àqueles de uma orientaçāo mais adequada ao desenvolvimento das forças produtivas da nação e real bem-estar de todo o povo.

A partir de 01/06/41, conforme Circular n 5 de 31/03/41 do SFCF, as farinhas de milho e de arroz deixariam de constar na mistura destinada à confecçāo do pāo misto. Medida que, na parte referente ao segundo produto, representando $3 \%$ da mistura, precisou ser antecipada devido a escassez da farinha de arroz no mercado e conseqüente grande alta nos seus preços, per- 


\begin{tabular}{lrccc}
\hline Ano & $\begin{array}{c}\text { Farinha } \\
\text { de trigo }\end{array}$ & $\begin{array}{c}\text { Trigo em } \\
\text { gräo }\end{array}$ & $\begin{array}{c}\text { Total de } \\
\text { trigo }\end{array}$ & $\begin{array}{c}\text { Total da } \\
\text { importação }\end{array}$ \\
\hline 1925 & 143.414 & 296.542 & 439.956 & 3.376 .832 \\
1931 & 36.412 & 283.761 & 320.173 & 1.880 .934 \\
1935 & 31.341 & 434.463 & 465.804 & 3.855 .917 \\
1936 & 46.204 & 617.075 & 714.563 & 4.268 .667 \\
1937 & 40.260 & 668.359 & 708.619 & 5.314 .551 \\
1938 & 33.632 & 536.494 & 570.126 & 5.195 .570 \\
1939 & 18.411 & 353.592 & 372.003 & 4.993 .992 \\
1940 & 15.926 & 471.309 & 487.235 & 4.964 .149 \\
1941 & 17.705 & 482.653 & 500.358 & 5.524 .986 \\
1942 & 16.653 & 572.967 & 589.620 & 4.694 .873 \\
1943 & 29.283 & 772.904 & 802.187 & 6.229 .232 \\
1944 & 117.423 & 1.097 .323 & 1.214 .746 & 8.128 .741 \\
1945 & 243.990 & 1.224 .535 & 1.468 .525 & 8.747 .086 \\
\hline
\end{tabular}

Fonte: ANUÁRIO ESTATÍSTICO DO BRASIL 1956. Rio de Janeiro, IBGE, v. 17,1956 . p. $526,532-3$.

(*) Ao mencionar Cruzeiro a referência é sempre feita ao Cruzeiro velho, equivalente a um mil réis $(1 \$ 000)$.

mitindo-se a sua substituição pela farinha de raspa de mandioca, de acordo com a Circular no 7 de 01/04/41 do SFCF. 12

Dessa maneira a produção do pão misto continuaria a ser feita apenas com o concurso da farinha de mandioca devido à falta, até 1940 , de boa resposta da produção dos dois outros cereais às necessidades de consumo. A quantidade produzida de milho estaria, ainda, de modo geral, regredindo no período 1935/45, enquanto que a de arroz só passaria a apresentar um crescimento firme a partir de 1941 , bem inferior àquele da mandioca. A quantidade desta última cresceria permanentemente nesse espaço de tempo, chegando em 1945 a ser $151,37 \%$ maior que a de 1935 , tendo a sua participação na produção total desses quatro, tubérculo e cereais citados neste texto, crescido de $37,88 \%$ em 1935 para $61,23 \%$ em 1945.

Isso seria, também, explicado e acompanhado por um decréscimo no preço da tonelada do referido tubérculo igual a 38,21\% de 1935 a 1940 e de $40,97 \%$ ate 1945 , enquanto que, para os mesmos períodos, o preço de mil quilos de milho cresceria $12,03 \%$ e $45,33 \%$. No caso do arroz já verificaríamos uma oscilaçāo mais violenta, principalmente em 1936, quando o preço da tonelada cresceria de $70,14 \%$ sobre o do ano anterior, baixando a partir

(12) LEX: coletânea de legislaçāo e jurisprudência, edição federal, São Paulo, Lex Editora, v. 5, 1941. p. 54-5 ( $3^{2}$ secção, marginália). ANUÁRIO ESTATÍSTICO DO BRASIL $1939 / 1940$. Rio de Janeiro, IBGE, v. S, [1941]. p. 1.312. 
de 1937, embora registrando em 1940 e 1945 acréscimos de $35,55 \%$ e $34,44 \%$ sobre o preço verificado no ano base de 1935.13

Todavia, existiria ainda, como fator adicional favorecendo a opçāo pela farinha de mandioca, o fato de sua composição com a de trigo permitir um aumento da quantidade de pão produzida, ultrapassando de $40 \%$ a $50 \%$ sobre aquela obtida pelo uso exclusivo de farinha de trigo, ao mesmo tempo que a mistura com milho possibilitava um crescimento máximo de $16,67 \%$. 14

Por outro lado, do uso da farinha de arroz obter-se-ia um pão mais branco e de maior durabilidade, o qual, numa associaçāo de ate $15 \%$ com farinha de trigo, não sofreria alteração no seu aspecto e qualidades físicas. O seu emprego permitiria melhor conservação do sabor característico do pão, que com o tempo tornar-se-ia menos elástico e borrachento que o produto comum. Mesmo na proporção de $50 \%$, seria, no referente a estes últimos aspectos, a farinha de arroz aquela que melhores resultados daria na produção do pão misto, embora da composição com mais de $20 \%$ desse cereal resultasse um pão de tamanho inferior, porque cresceria menos no forno, com textura mais compacta e portanto mais pesado. 15

Essa política de emprego parcial de sucedâneos permitiria, ao país, enfrentar a redução na importação de trigo ocorrida a partir de 1939 , decorrente das condiçōes criadas pelo estado de guerra presente no hemisfério norte. Ela também se constituiria em medida determinada pelo aumento real de $49,43 \%$ no preço do trigo comprado no exterior entre 1935 e 1936 , além da carência de divisas, na época, sofrida pelo Brasil. Seria, assim, gerado um quadro favorável ao uso de substitutos locais, que acabaria prejudicado pelas quedas daqueles preços observadas já em 1937 e, principalmente, por acordo de comércio com a Argentina de 1941.

Convém recordar que o simples aumento da taxa de extraçăo constituiria um meio de obter-se maior quantidade de farinha. Poder-se-ia elevar essa proporção do nível de $60 \%$ e $70 \%$, quando se obtém uma mercadoria mais pura e branca, embora de menor valor nutritivo, ate aquela de $80 \%$ e $85 \%$. Teríamos, agora, graças à retenção do remoído, um aumento da produçāo de farinha a partir da mesma quantidade de grãos, além de conseguir-se conservar elementos básicos para a alimentação humana, como sais minerais e vitaminas, que de outra forma perder-se-iam juntamente com o farelo. ${ }^{16}$

(13) ANUÁRIO ESTATÍSTICO DO BRASIL 1939/1940. Rio de Janeiro, IBGE, v. 5, [1941]. p. 1.312-4. Idem 1956. v. 17, 1956. p. 496, 503-5.

(14) AMARAL, F. Pompeo do. Op. cit. p. 403.

(15) MELLO, A. da Silva. Op. cit. p. 171-7. Convém lembrar que a mandioca cozida pode ser misturada com a farinha de trigo, do que resulta um pảo de ótima qualidade, enquanto que 0 arroz, aqui, de acordo com MELLO, A. S. (op. cit. p.174-7), também pode, cozido como papa, ser batido com a massa do pāo, ou empregado na forma de farinha de arroz inteiramente descorticada ou integral.

AMARAL, F. Pompeo do. Op. cit. p. 402. 
A farinha integral daria um pāo que melhor atenderia às necessidades fisiológicas do ser humano. Contudo na farinha de extração a $85 \%$ já se contaria com a presença, em relação àquela de $70 \%$, de quatro vezes mais vitamina $\mathrm{B}_{2}$ e cinco vezes a de ácido nicotínico, além de $2 / 3$ a $7 / 10$ da vitamina $B_{1}$. Fora isso, a farinha a $85 \%$ retém o germe do trigo, o qual contém provitamina A e vitamina E. 17

Por outro lado, acima da taxa de extração de $85 \%$ a panificação seria mais difícil, podendo aí o pāo tornar-se pesado, ficando assim alterados seu aspecto, sabor, contextura e digestibilidade, características que acarretariam aumento da rejeição do consumidor, a qual já afeta o produto com nível de $80 \%$ a $85 \% .^{18}$

Preço da Tonelada de Trigo Importado (Cr\$ de 1939)

\begin{tabular}{cccc}
\hline Ano & $\begin{array}{c}\text { Valor real do } \\
\text { total importado } \\
(\text { Cr\$1.000,00) }\end{array}$ & $\begin{array}{c}\text { Quantidade estimada } \\
\text { de trigo importado } \\
\text { convertida para grão } \\
\text { (Toneladas) }\end{array}$ & $\begin{array}{c}\text { Preço real esti- } \\
\text { mado da tonelada } \\
\text { de grão } \\
\text { (Cr\$/t) }\end{array}$ \\
\hline 1925 & 323.735 & 739.869 & 437,56 \\
1931 & 416.350 & 877.636 & 474,40 \\
1935 & 528.722 & 942.342 & 561,07 \\
1936 & 827.999 & 987.611 & 838,39 \\
1937 & 712.896 & 985.894 & 723,32 \\
1938 & 568.421 & 1.094 .469 & 519,36 \\
1939 & 372.003 & 1.011 .819 & 369,66 \\
1940 & 477.213 & 881.976 & 541,07 \\
1941 & 452.813 & 918.844 & 492,81 \\
1942 & 460.640 & 966.546 & 476,58 \\
1943 & 526.369 & 1.076 .718 & 488,86 \\
1944 & 628.750 & 1.298 .058 & 484,38 \\
1945 & 651.231 & 1.279 .251 & 509,07 \\
\hline
\end{tabular}

Fonte: ANUÁRIO ESTATÍSTICO DO BRASIL 1956, Rio de Janeiro, IBGE, v. 17, 1956. p. 526, 530-3. Deflator: HADDAD, C. L. S. Crescimento do produto real no Brasil 1900/1947. Rio de Janeiro, Fundação Getúlio Vargas, 1978. p. 166. A farinha de trigo importada foi convertida para grão supondo-se que 0,75 unidade de farinha resultaria de uma unidade de grão.

Desse modo, não poderíamos, na confecção do pão, sem afetar profundamente a qualidade do produto, empregar farinha com extraçāo acima de $85 \%$, nem prescindir do uso de farinha de trigo. Esta última deveria, ainda, figurar como, pelo menos, um terço do total da mistura com a farinha de mandioca, um quarto naquela com farinha de milho e $50 \%$ com a de arroz, embora a proporção ideal de mistura fosse com $10 \%$ a $15 \%$ e quando muito

(17) Idem. Ibidem. p. 397-9.

(18) Idem. Ibidem. p. 399. MELLO, A. da Silva. Op. cit. p. 160-1. 
de $20 \%$ de farinha sucedânea. Isso ocorreria por contar o trigo com maior quantidade de glúten, que, no caso deste cereal, seria, ao contrário do que ocorreria com o milho, liberado, quando sua farinha fosse amassada com água. Isso possibilitaria ao glúten garantir a liga e através do processo de fermentaçāo o crescimento e a porosidade do pão, à medida que retém bolhas de gás carbônico, que se formam com aquele processo, numa ação que se intensificaria com o calor do forno, o qual provocaria a solidificação e endurecimento da textura da massa. Desse modo obtém-se um alimento leve porque poroso e rendilhado como uma esponja, enquanto que da pequena quantidade ou ausência de glúten resultaria uma massa mais compacta e densa. 19

Preço da Tonelada Produzida

\begin{tabular}{|c|c|c|c|c|c|c|c|}
\hline \multirow{2}{*}{ Ano } & \multicolumn{3}{|c|}{$\mathrm{Cr} \$ / \mathrm{t}$} & \multirow{2}{*}{ Deflator } & \multicolumn{3}{|c|}{$\mathrm{Cr} \$$ de $1939 / \mathrm{t}$} \\
\hline & Mandioca & Milho & $\begin{array}{l}\text { Arroz } \\
\text { com } \\
\text { casca }\end{array}$ & & Mandioca & Milho & $\begin{array}{l}\text { Arroz } \\
\text { com } \\
\text { casca }\end{array}$ \\
\hline 1920 & 30,00 & - & - & 74,1 & 40,49 & & - \\
\hline 1925 & - & 291,08 & 537,16 & 135,9 & - & 214,19 & 395,26 \\
\hline 1931 & 81,95 & 181,68 & 271,11 & 76,9 & 106,57 & 236,25 & 352,55 \\
\hline 1935 & 97,94 & 187,50 & 330,20 & 88,1 & 111,17 & 212,83 & 374,80 \\
\hline 1936 & 101,59 & 198,26 & 550,32 & 86,3 & 117,72 & 229,73 & 637,68 \\
\hline 1937 & 101,24 & 232,88 & 590,03 & 94,4 & 107,25 & 246,69 & 625,03 \\
\hline 1938 & 85,61 & 238,06 & 543,89 & 100,3 & 85,35 & 237,35 & 542,26 \\
\hline 1939 & 77,18 & 228,35 & 529,71 & 100,0 & 77,18 & 228,35 & 529,71 \\
\hline 1940 & 70,13 & 243,45 & 518,72 & 102,1 & 68,69 & 238,44 & 508,05 \\
\hline 1941 & 76,59 & 248,17 & 567,14 & 110,5 & 69,31 & 224,59 & 513,25 \\
\hline 1942 & 89,35 & 280,04 & 614,38 & 128,0 & 69,80 & 218,78 & 479,98 \\
\hline 1943 & 99,02 & 409,69 & 788,60 & 152,4 & 64,97 & 268,82 & 517,45 \\
\hline 1944 & 126,76 & 565,40 & $1.005,48$ & 193,2 & 65,61 & 292,65 & 520,43 \\
\hline 1945 & 147,97 & 697,49 & $1.137,12$ & 225,5 & 65,62 & 309,31 & 504,27 \\
\hline
\end{tabular}

Fonte: ANUÁRIO ESTATÍSTICO DO BRASIL 1939/1940. Rio de Janeiro, IBGE, 1941. p. 1.312-4. Idem 1956. v.17, 1956. p. 496, 503-4. Deflator: HADDAD, C. L. S. Op. cit. p. 166.

A farinha mista continuou a ser empregada no país, a partir de meados de 1941, limitada à associaçāo com a de mandioca, a qual, em virtude do Convênio Econômico Argentino-Brasileiro de 09/04/41, ficaria reduzida à proporção de $10 \%$, acabando por desaparecer em fins de 1943 , quando, devido ao referido acordo bilateral, cessou a obrigatoriedade, então transfor-

(19) AMARAL, F. Pompeo do. Op. cit. p. 402. MELLO, A. da Silva. Op. cit. p. 161-2, 174. 
mada em proibição, do uso daquela mistura, que teria chegado a alcançar, em 1941, 23\% de sucedâneos da composiçāo mista panificável. ${ }^{20}$

Participação Percentual Obrigatória de Outros Produtos
Além do Trigo na Composição da Farinha Mista

\begin{tabular}{lrrc}
\hline Farinha de & 1939 & 1941 & 1942 \\
\hline & & & \\
Mandioca & 3 & 15 & 10 \\
Milho* & 5 & 5 & - \\
Arroz* & 1 & 3 & - \\
\hline
\end{tabular}

Total

Fonte: EDWARDS, C. D. Controle de mercados e preços. In: COOKE, M. L. Op. cit. p. 400.

(*) De 01/09/39 a 31/05/41

A fim de combater os efeitos negativos daquele Tratado e amparar os produtores de farinha de raspa de mandioca e seus fornecedores, num período em que aqueles teriam feito importantes aquisiçōes de maquinaria, foi criada, através do Decreto-Lei no 5.031 de 04/12/42, a Comissão Executiva dos Produtos de Mandioca (CEPM), para controlar a produçāo, o comércio e a exportação dessas mercadorias. ${ }^{21}$

Conforme o referido Decreto-Lei no 5.031/42, a CEPM, criada junto ao Ministério da Agricultura, teria sede na cidade do Rio de Janeiro, devendo ser constituída por um representante do Serviço de Economia Rural, que seria seu presidente, outro do SFCF, mais um para cada uma das regiőes Norte, Centro e Sul do país.

A essa Comissāo, de acordo com o referido instrumento legal, competiria o estudo sistemático das zonas de cultivo da mandioca; montagem e desapropriação de instalações necessárias à organização racional da industrializaçāo do produto; tomar medidas destinadas ao amparo e controle da produção e transformação da mandioca, transporte e comercialização dos produtos derivados; negociar, com a garantia dos Estados produtores, as operaçōes de crédito necessárias ao amparo total da mandioca; cobrar taxa de $10 \%$ sobre o

(20) EDWARDS, C. D. Controle de mercados e preços. In: COOKE, M. L. (coord.). A Missão Cooke no Brasil. Rio de Janeiro, Fundação Getúlio Vargas, 1949. p. 400. SALES, A. O Ministério da Agricultura no governo Getúlio Vargas 1930/1944. Rio de Janeiro, Serviço de Documentaçāo do Ministério da Agricultura, 1945. p. 203.

(21) SALES, A. Op. cit. p. 203. ANDRADE, A. Op. cit. v. 1. p. 108-9. SCHWARTZMAN, S. (org.). Estado Novo: um auto-retrato (arquivo Gustavo Capanema). Rio de Janeiro, Fundaçāo Getúlio Vargas, 1983.p. 321-2. 
valor de venda dos produtos de mandioca, para constituição de fundo financeiro para sua operaçāo e auxflios a serem dados; organizar cooperativas, para o financiamento aos agricultores e industriais da mandioca e administração das fábricas; nomear e substituir, durante três anos, as diretorias das cooperativas que organizar, saídos os diretores do quadro de associados, podendo o gerente ser, a ele, estranho; delimitar a área de ação dessas cooperativas, podendo criar apenas uma em cada zona; estabelecer convênios com os países consumidores ou realizar aqueles estabelecidos a respeito de produtos da mandioca.

Seria encontrado novo uso para os excedentes da fabricação de farinha, na geração de álcool. Optar-se-ia, assim, pelo incentivo da produçāo de álcool de origem amilácea, regulamentado através do Decreto-Lei no 5.068 de 11/12/42. Com a mesma finalidade recorreria, ainda, o Governo a outros meios. Primeiro colocaria no mercado dos Estados Unidos da América o encalhe de fécula produzida em 1943, totalizando aproximadamente 30 mil toneladas. Depois, obrigaria as fiaçōes e tecelagens do país "a adquirir e consumir, nos serviços de engomagem de fios, acabamento de tecidos e nos trabalhos de estamparia, a fécula ou amido de mandioca de produçāo nacional". Para isso as fábricas deveriam obrigatoriamente adquirir quotas desses produtos, fixadas mensalmente pela CEPM, conforme o consumo de cada uma. A referida Comissão, também, fixaria os preços mínimos a serem pagos pela fécula ensacada, enquanto que a mercadoria destinada às fiaçōes e tecelagens gozaria de uma redução de $20 \%$ nas tarifas ferroviárias e fretes de empresas de cabotagem. ${ }^{22}$

Concomitantemente, teríamos mais uma demonstração da pouca coerência e do imediatismo na política econômica governamental. Política que pela sua inconstância revelaria um desligamento da realidade local, além de liberdade de manobra limitada. Assim, repetindo ato semelhante, do SFCF, de 1939, a Coordenação da Mobilizaçāo Econômica, pela Portaria 117 de 04/08/43, alegando pouca regularidade nas importaçōes de trigo e necessidade de melhor aproveitamento da supracitada matéria-prima, permitiria, a título de emergência, níveis mais altos de extração na produção de sua farinha. Àquela destinada ao abastecimento do município do Rio de Janeiro, Niterói, Petrópolis e Nova Iguaçu, seria autorizado o de $85 \%$, enquanto que o de $80 \%$, com mistura oficial, ficaria reservado às cidades de São Paulo e Santos. Para outros pontos do país, onde as dificuldades de transporte impediriam o uso de farinha de alta extração, mais difícil de ser conservada, seria mantida a proporçāo usual de $75 \%$, taxa igualmente empregada com mistura oficial, na fabricação de massas e outros produtos, também no, então, Distrito Federal, Barra Mansa e Estado de São Paulo. ${ }^{23}$

Dessa maneira o curto período da produção e uso obrigatório da farinha e do pão misto encerrava-se, aparentemente, de modo suave e menos custoso, à medida que, para aquela ocasiāo, pôde-se afastar o perigo da paralisa-

(22) Decreto-Lei n-5.447, de 30/04/43. ANDRADE, A. Op. cit. v. 1.p. 114. SALES, A. Op. cit. p. 204-5.

(23) LEX: coletânea de legislaçāo e jurisprudência, ediçāo federal. Sāo Paulo. Lex Editora, v. 7, 1943. p. 135-6 (3² secçāo, marginália). 
ção das "fábricas de farinha [sic] de raspas de mandioca [que] alarmadas com os compromissos que haviam assumido, clamavam pela indenização de sua maquinaria, que subia a mais de 30 milhōes de cruzeiros, [através] de novas utilizações e [outros] mercados para aquele produto". 24

O emprego da farinha mista vigorou de agosto de 1938 a dezembro de 1943, acarretando uma redução significativa na importação de trigo, representando uma economia de 770.500 toneladas deste cereal, além de estimular a produção nacional sucedânea. Todo esse esforço de substituição de importação serià, então, anulado em benefício do convênio com a Argentina, pelo qual os dois países obrigar-se-iam a reduzir, gradualmente, o uso de substitutos nos gêneros alimentícios, até a sua completa extinção após dezembro de 1943.25

\section{Importação Brasileira de Trigo}

\begin{tabular}{ccc}
\hline Ano & $\begin{array}{c}\text { Evolução da quantidade } \\
\text { importada de trigo (\%) }\end{array}$ & $\begin{array}{c}\text { Participação do valor } \\
\text { do trigo na importação } \\
\text { total brasileira (\%) }\end{array}$ \\
\hline 1925 & 78,51 & 13,03 \\
1931 & 93,13 & 17,02 \\
1935 & 100,00 & 12,08 \\
1936 & 104,80 & 16,74 \\
1937 & 104,62 & 13,33 \\
1938 & 116,14 & 10,97 \\
1939 & 107,37 & 7,45 \\
1940 & 93,59 & 9,81 \\
1941 & 97,51 & 9,06 \\
1942 & 102,57 & 12,56 \\
1943 & 114,26 & 12,88 \\
1944 & 137,75 & 14,94 \\
1945 & 135,75 & 16,79 \\
\hline
\end{tabular}

Fonte: ANUÁRIO ESTATÍSTICO DO BRASIL 1956. Rio de Janeiro, IBGE, v. 17,1956 . p. $526,532-3$.

(24) ANDRADE, A. Op. cit. v. 1.p. 108.

(25) SCHWARTZMAN, S. (org.). Op. cit. p. 321-2, 511-2. Seria firmado em Buenos Aires, a 09/04/41, entrando em vigor, provisoriamente, a 14/04/41, enquanto não fosse ratificado, "Convênio para a supressăo de sucedâneos nos gêneros alimentícios, facilidades recíprocas para a importaçảo e venda de produtos industriais e regime de câmbios, entre o Brasil e a Argentina". RELATÓRIO apresentado ao Presidente da República dos Estados Unidos do Brasil pelo Ministro de Estado das Relaçōes Exteriores. 1941. Rio de Janeiro, Imprensa Nacional, 1944. p. 30. 
Evolução do Preço Real da Tonelada $(1935=100)$

\begin{tabular}{lcccc}
\hline Ano & Mandioca & Milho & $\begin{array}{c}\text { Arroz } \\
\text { com } \\
\text { casca }\end{array}$ & $\begin{array}{c}\text { Trigo } \\
\text { importado }\end{array}$ \\
\hline 1925 & $36,42^{*}$ & 100,64 & 105,46 & 77,99 \\
1931 & 95,86 & 111,00 & 94,06 & 84,55 \\
1935 & 100,00 & 100,00 & 100,00 & 100,00 \\
1936 & 105,89 & 107,94 & 170,14 & 149,43 \\
1937 & 96,47 & 115,91 & 166,76 & 128,92 \\
1938 & 76,77 & 111,52 & 144,68 & 92,57 \\
1939 & 69,42 & 107,29 & 141,31 & 65,88 \\
1940 & 61,79 & 112,03 & 135,55 & 96,43 \\
1941 & 62,35 & 105,52 & 136,94 & 87,83 \\
1942 & 62,79 & 102,80 & 128,06 & 84,94 \\
1943 & 58,44 & 126,31 & 138,06 & 87,13 \\
1944 & 59,02 & 137,50 & 138,85 & 86,33 \\
1945 & 59,03 & 145,33 & 134,54 & 90,73 \\
\hline
\end{tabular}

Fonte: ANUÁRIO ESTATÍSTICO DO BRASIL 1939/1940. Rio de Janeiro, IBGE, v. 5, [1941]. p. 1.312-4. Idem 1956. v. 17, 1956. p. 496, 503, 504, 526, 530-3.

Deflator: HADDAD, C. L. S. Op. cit. p. 166.

(*) 1920 .

Esse pão misto de mandioca teria sido mal aceito pelo público, o que possivelmente mostraria o acerto da Comissão do Pão Misto, criada em São Paulo em 1933, durante a Interventoria de Waldemar Castilho de Lima, ao recomendar como melhor tipo de pão misto aquele preparado com $70 \%$ de farinha de trigo, $10 \%$ de fécula de mandioca, $10 \%$ de amido de milho e $10 \%$ de farinha de arroz. Assim, ter-se-ia uma mistura onde o gosto de cada um dos sucedâneos seria disfarçado, parecendo que o pāo havia sido confeccionado só com farinha de trigo. Fenômeno que possivelmente ocorreria devido ao fato da farinha de arroz em mistura de até $15 \%$ com a de trigo não alterar a consistência e a porosidade da massa do pão. Fora isso, com ela obtém-se um produto mais branco e de aspecto mais agradável, que se conserva melhor e por mais tempo do que o tradicional de farinha de trigo pura. 26

Contudo, a abundância, o baixo preço e a maior produtividade oferecida pela mandioca na fabricação do pão misto favoreciam a predominância absoluta do seu uso nessa atividade. Produção que se caracterizaria pela sua intermitência e, talvez, por isso mesmo geradora de uma mercadoria mal aceita, à medida que o povo não teria tempo de com ela se acostumar, dei-

(26) MELLO, A. da Silva. Op. cit.p. 167, 171-2, 178. AMARAL, F. Pompeo do. Op. cit. p. $405-$
7 . 
xando, graças àquela característica, de se beneficiar da continuidade nos estudos e investimentos para o seu aperfeiçoamento.

Confirmando essa afirmação, verificar-se-ia que no imediato após guerra - Brasil voltaria a enfrentar problemas de abastecimento de trigo, devido a sua escassez em todo o Mundo, acompanhada de queda na produçāo da Argentina, que além disso comprometera-se a vender para a UNRRA (United Nations Relief and Rehabilitation Administration).

Formava-se, naquela ocasião, uma nova situação de dificuldades no abastecimento, à medida que o Governo brasileiro só estava conseguindo assegurar $50 \%$ do trigo requerido pelas nossas necessidades. Isso conduziria as autoridades nacionais para o antigo recurso da farinha de maior extração e do pão misto, que justamente havia sido abandonado em benefício do comércio exportador argentino.

Nesse sentido, o Prefeito do Distrito Federal determinaria, no primeiro semestre de 1946, a confecção de pão misto com $30 \%$ de farinha de milho. Medida semelhante seria tomada pelo Interventor Federal em São Paulo, em abril do mesmo ano, autorizando, a título precário, os panificadores e fabricantes de massas alimentícias em geral, a adicionar à farinha de trigo até $30 \%$ (aumentados para $35 \%$ no mês seguinte) de farinha de milho desgerminada, ou farinha de raspas de mandioca, permissão que a partir de maio seria estendida para as farinhas de arroz e de soja. Fora isso, os panificadores e produtores de massas alimentícias ficavam também proibidos de utilizar farinha de trigo na produção de pães doces, panetones, roscas e biscoitos. Ao mesmo tempo, o Governo do Estado passaria a ter à sua disposição toda a farinha de trigo pura existente ou em trânsito no território sob sua jurisdição ou, ainda, objeto de contratos de importação e destinados aos portos paulistas. 27

Tais acontecimentos viriam a comprovar o oportunismo, a visāo de mundo curta e restrita, a submissão servil e irrefletida a hábitos e padrões dos países desenvolvidos, acrescidos da ação anárquica e desprovida de objetivos mais profundos e permanentes, além de mais adequados à nação, imperantes no Brasil.

Teríamos, como política, atos mo:nentâneos de colocação de remendos e execução de consertos apenas temporários, fugindo-se sempre ou quase sempre da adoção de soluçōes mais permanentes e verdadeiras, condutoras a situaçōes e organizaçōes de caráter mais duradouro e seguro, embora de realização dificultosa.

A opçāo seguida seria costumeiramente aquela menos trabalhosa e conforme padrōes, preconceitos e interesses de origem externa à naçāo, deixando-se de lado o desenvolvimento e aproveitamento dos produtos locais.

Assim normalizando-se a oferta internacional de trigo, a sua importação seria retomada, fazendo com que todos os estudos e conquistas para o aproveitamento de sucedâneos nacionais acabassem por ser abandonados. Eles seriam esquecidos para, no advento de nova crise de abastecimento, voltarem à baila, recomeçando-se, geralmente, as experiências quase da estaca zero.

(27) AMARAL, F. Pompeo do. Op. cit. p. 403, 510-2. Decretos do Estado de São Paulo ns 15.768, de $19 / 04 / 46$, e 15.786 , de $06 / 05 / 46$. 
Comprovar-se-ia, desse modo, que entre nós, até a memória histórica tenderia a ser estratégica e extremamente fraca, principalmente no referente aos esforços e às conquistas locais tendentes a possibilitar maior independência dos mercados e da tutela do exterior.

Recebido em 26 de agosto de 1988.

\begin{abstract}
The search for goods substitute those that are not easily produced in Brazil should tend to occur periodically and at times in which there are problems of importation. Here we point out successive attempts at rec'ucing the consumption of foreign wheat, substituting it for other bread flours, such as manioc flour which could become important due to its abundance and low costs. In fact, this product had been researched and used in Brazil by the last half of the 19th century and it continued to be used upon occasion even after the Second World War.
\end{abstract}

Key-words: importation substitutes - technology-industry-nourishment 